\section{Effect of Ultrasound Frequency and Treatment Duration on Antibiotic Elution from Polymethylmethacrylate Bone Cement}

Alexander C. Wendling, M.D., ${ }^{1,2}$, Damon E. Mar, Ph.D. ${ }^{1}$, Jonathan C. Burkes, M.D. ${ }^{1}$, Terence E. McIff, Ph.D., MBA ${ }^{1}$

${ }^{1}$ University of Kansas Medical Center, Department of Orthopedic Surgery, Kansas City, KS ${ }^{2}$ University of Kansas School of Medicine-Wichita, Department of Orthopedic Surgery, Wichita, KS

Received Oct. 25, 2018; Accepted for publication January 16, 2019; Published online May 15, 2019

\section{ABSTRACT}

Introduction. The objective of this study was to evaluate the effect of ultrasound frequency and treatment duration on antibiotic-impregnated polymethylmethacrylate (PMMA) antibiotic elution rates and mechanical strength.

Methods. Two batches of PMMA were prepared: one with five grams of vancomycin powder and one without. Each batch was divided into two frequency groups: $\mathrm{kHz}$ and $\mathrm{MHz}$. Each frequency group was divided into two duration groups: two minutes and ten minutes. Elution samples were measured daily using flow injection analysis. After one week of elution, ultrasound treatments were done daily until each group's average concentration fell below those of non-ultrasound control groups. After elution testing, compression testing determined mechanical properties. Paired t-tests were used to compare daily elution amounts to baseline values. Univariate ANOVAs were used to test for effects of both frequency and treatment duration on antibiotic elution amounts and on mechanical properties.

Results. All ultrasound treatments resulted in significant increases in antibiotic elution. Frequency and duration had significant effects of increasing antibiotic elution ( $\mathrm{p}<0.001)$. The $\mathrm{kHz}$ group produced significantly greater antibiotic elution than the MHz group $(\mathrm{p}<0.001)$. The 10-minute duration produced significantly greater antibiotic elution than the two-minute duration (both $\mathrm{p}<0.001$ ). Frequency and duration did not have significant effects on yield stress $(p=0.841$ and $\mathrm{p}=0.179$, respectively). Frequency had a significant effect $(\mathrm{p}=$ 0.024) on modulus, but duration did not ( $\mathrm{p}=0.136)$.

Conclusions. Ultrasound frequency and treatment duration significantly affect antibiotic elution from PMMA which may be helpful for treatment of periprosthetic joint infections during revision arthroplasty. Kans J Med 2019;12(2):45-49.

\section{INTRODUCTION}

Periprosthetic joint infection (PJI) is a devastating condition that can lead to significant patient morbidity. Infection rates for primary total knees and hips range from $0.3 \%-3 \% .^{1-3}$ Infection rates following revision due to infection were greater than primary rates from $5 \%$ - 10\% despite aggressive debridement strategies and systemic antibiotic use. ${ }^{4-6}$ Two-stage revision is considered the standard method for treatment of chronic PJIs. ${ }^{7}$ As part of this strategy, antibiotic-loaded polymethylmethacrylate (PMMA) bone cement is used to maintain the space of the removed implants and to provide high concentrations of antibiotic delivery needed to eradicate and inhibit biofilm
KANSAS JOURNAL of MEDICINE

formation. ${ }^{8,9}$ This technique allows for increased local antibiotic concentrations that would otherwise not be tolerated if delivered systemically. ${ }^{10}$ The antibiotic elution duration profile typically is biphasic with a majority of the net total elution occurring within the first few days. ${ }^{11}$ The secondary, long-term phase may see concentration levels fall below critical physiological thresholds, such as minimum inhibitory concentrations (MIC) or minimum biofilm eradication concentration (MBEC), to provide adequate therapeutic effects. ${ }^{8,12,13}$ Unfortunately, as much as $78 \%-85 \%$ of the antibiotic can remain entrapped within the cement even after months of elution. ${ }^{14,15}$

Many factors can affect antibiotic release from bone cement. Antibiotic release is dependent on type of cement, antibiotic selection, preparation technique, and surface properties. ${ }^{11,16-18}$ Methods have been investigated to increase the permeability of cement so as to increase antibiotic elution and reduce antibiotic entrapment. Such techniques include the addition of antibiotic-loaded microspheres, poragens, modified mixing techniques, and use of ultrasound (US) exposure. ${ }^{19-22}$ Several techniques, however, produce undesirable sideeffects on the mechanical integrity of the cement and few have yet to be accepted and utilized widely by surgeons. ${ }^{23-25}$

US is effective in increasing antibiotic elution from standard bone cement. ${ }^{22,26-28}$ There remains, however, limited understanding of how sensitive elution rates are to varied US parameters and techniques. In particular, no study to date has shown the effect of clinically-relevant US frequencies and treatment durations on long-term antibiotic elution from bone cement. While studies have demonstrated increased antibiotic elution over short periods, few have evaluated elution following US treatment for more than one week, ${ }^{17,29}$ which is far less than the length of time antibiotic spacers typically remain implanted in the body. ${ }^{30-32}$

The goal of this study was to use clinical US devices to determine if a higher or lower frequency would yield greater increases in antibiotic elution and to compare the effect of both shorter and longer daily treatment durations. The primary hypothesis was that US frequency and treatment duration have significant effects on antibiotic elution rates. It was hypothesized that US treatment in the $\mathrm{kHz}$ range would yield significantly greater antibiotic elution compared to the $\mathrm{MHz}$ range. Additionally, longer treatment durations would yield significantly greater total antibiotic elution. Finally, both frequencies at either treatment duration would not have a significant effect on the mechanical integrity of the cement.

\section{METHODS}

The specimen preparation techniques used in this study followed previously established methods used by our lab for antibiotic elution study. ${ }^{20,26}$ For the current study, two $40 \mathrm{~g}$ batches of SmartSet MV (DePuy, Blackpool, United Kingdom) PMMA cement were prepared: one with five grams (12.5\% by weight) of vancomycin powder (Sagent Pharmaceuticals Inc., Schaumburg, Illinois) added using a standard mixing technique and one without antibiotic to serve as a control. 
KANSAS JOURNAL of MEDICINE

ULTRASOUND FREQUENCY ON ANTIBIOTIC ELUTION continued.

Both preparations were made with a SmartMix cement mixing system (DePuy, Blackpool, United Kingdom) using a one Hz stir rate and a $30 \mathrm{kPa}$ vacuum to remove air bubbles. Forty specimens were molded from each batch in accordance with ASTM standard F451-99a specifications. ${ }^{33}$ All specimens were cured for one hour in the molds before being removed, individually massed, and visually inspected for defects. Thirty specimens from the antibiotic group and thirty specimens from the control group were placed in individual $50 \mathrm{~mL}$ vials with $10 \mathrm{~mL}$ of phosphate buffered saline (PBS) and stored in a $37^{\circ} \mathrm{C}$ incubator.

Twenty specimens of both batches were divided into two US frequency ranges ( $\mathrm{kHz}$ and $\mathrm{MHz}$ ) and two treatment duration groups (two minutes and ten minutes) with five specimens in each group. The remaining ten specimens from the vancomycin batch received no US treatment for the duration of the study and provided baseline elution control values. The $\mathrm{kHz}$ frequency group was treated using a commercial therapeutic cavitation US machine which operates at $40 \mathrm{kHz}$ (Dia Panda Box, China). The MHz frequency group was treated using a Chattanooga Intellect clinical muscle therapy US machine set to run at $1 \mathrm{MHz}$ (DJO, Guildford, United Kingdom). The output intensities of both machines were set to approximately $3 \mathrm{~W} / \mathrm{cm}^{2}$. For each US treatment, the transducer of the US machine was placed vertically in a clamp and then each specimen's vial was inverted and placed on top of the transducer head separated by a thin layer of US gel as shown in Figure 1 .

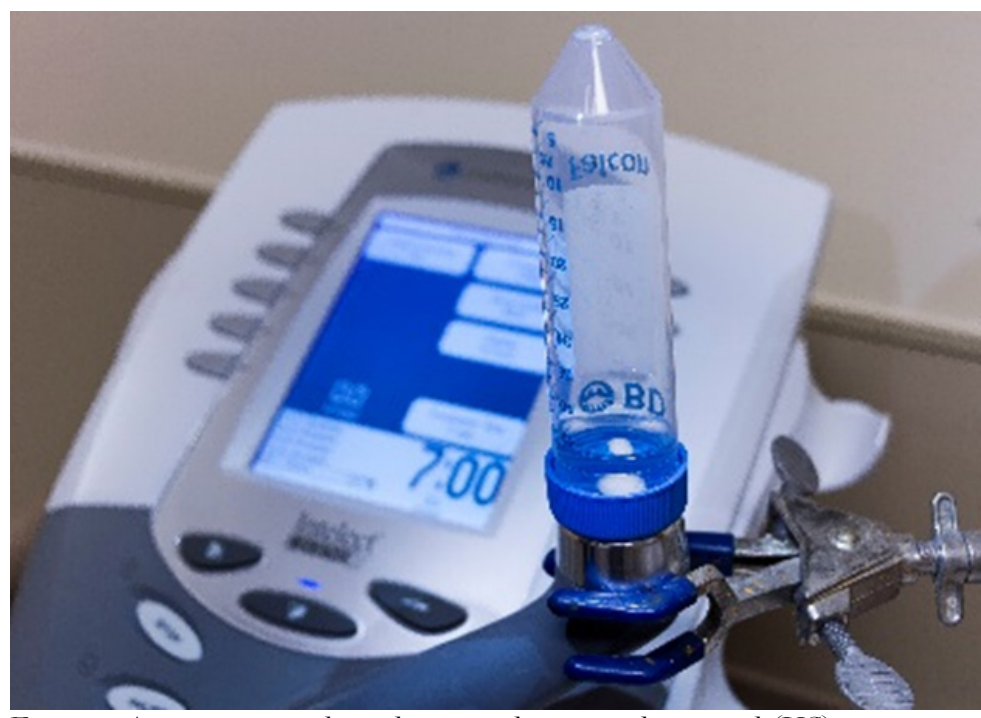

Figure l. A cement sample is shown undergoing ultrasound (US) treatment. The specimen is kept in its vile and placed directly on the transducer head with a thin layer of US gel.

US treatments were started after one week of standard elution and were done immediately following each day's solution replacement. Elution samples for concentration determination were taken just prior to each day's solution replacement.

Daily antibiotic elution concentrations were determined using a previously described and validated flow injection analysis (FIA) technique. ${ }^{26}$ Specimens made from the cement batch having no van- comycin were used to control for the presence of all solutes other than vancomycin. To do this, daily baseline FIA values of the nonantibiotic loaded groups were subtracted from the FIA of their corresponding frequency and treatment duration antibiotic loaded groups. US treatments were run daily on each group until its daily average vancomycin concentration fell to within $160 \%$ of the average value for the non-US group on that same day. Analysis was done using Matlab (The MathWorks, Natick, MA, USA) and Excel (Microsoft Corporation, Redmond, WA, USA) software.

All specimens were tested mechanically in compression once each group's US treatment period was concluded. Compression testing was done in accordance with ASTM F451-99a to evaluate offset yield stress and elastic modulus. ${ }^{33}$ Testing was done with a MTS 858 Mini Bionix II hydraulic load frame (MTS Systems, Eden Prairie, Minnesota). Offset yield stress results were compared to the minimum strength threshold defined by International Standards Organization (ISO) 5833:2002. ${ }^{34}$ Mechanical analysis also was done using Matlab and Excel software.

For total elution, univariate ANOVAs were used to test for significant effects of frequency and treatment time on average total elution increases. Post-hoc paired t-tests were used to compare net total elution amount averages of the four treatment groups. For mechanical properties, univariate ANOVAs were used to test for effects of frequency, treatment duration, and addition of antibiotic on offset yield stress and elastic modulus. Post-hoc paired t-tests were used to compare individual groups. Statistical analysis was calculated using Excel and SPSS (IBM Corporation, Armonk, NY, USA) software.

\section{RESULTS}

Average daily antibiotic elution concentrations for each group are shown in Figure 2.

All US treatment groups produced increased antibiotic elution significantly above the non-US group on the first day of US treatment. The $\mathrm{kHz}$ frequency group produced the longest sustained increases in elution to nine and 16 days after the start of US treatment for two and 10 minute treatment times, respectively. The MHz group sustained increases to six and five days after the start of US treatment for two and 10 minute treatment times, respectively.

The average net sum of increased antibiotic elution above non-US elution for each group is shown in Figure 3. This represents the amount of additional antibiotic that can be attributed to the US treatment over the course of the study.

US frequency and treatment duration each had significant univariate effects on increasing antibiotic elution ( $\mathrm{p}<0.001)$. The $\mathrm{kHz}$ groups each produced significantly greater antibiotic elution than the MHz groups $(\mathrm{p}<0.001)$. The 10-minute duration groups produced significantly greater antibiotic elution than the two-minute duration groups (both $\mathrm{p}<0.001$ ).

Results from the mechanical testing are shown in Figure 4. The addition of the antibiotic to the cement had a significant univariate effect of reducing both offset yield stress and elastic modulus (p 0.001). For offset yield stress, both US frequency and treatment duration did not have significant univariate effects $(p=0.841$ and $\mathrm{p}=0.179$, respectively). For elastic modulus, US frequency had a 
significant univariate effect $(\mathrm{p}=0.024)$, but treatment duration did $\operatorname{not}(\mathrm{p}=0.136)$. All groups maintained offset yield stresses significantly above the $70 \mathrm{MPa}$ limit specified by ISO 5833:2002 (p <0.001). ${ }^{34}$

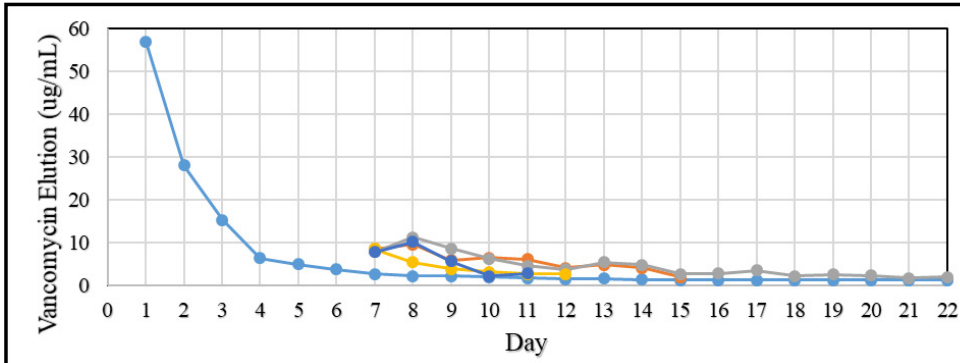

$\rightarrow-$ Non-Ultrasound $\rightarrow-\mathrm{kHz}-2 \mathrm{~min} \rightarrow \mathrm{kHz}-10 \mathrm{~min} \rightarrow \mathrm{MHz}-2 \mathrm{~min} \rightarrow \mathrm{MHz}-10 \mathrm{~min}$

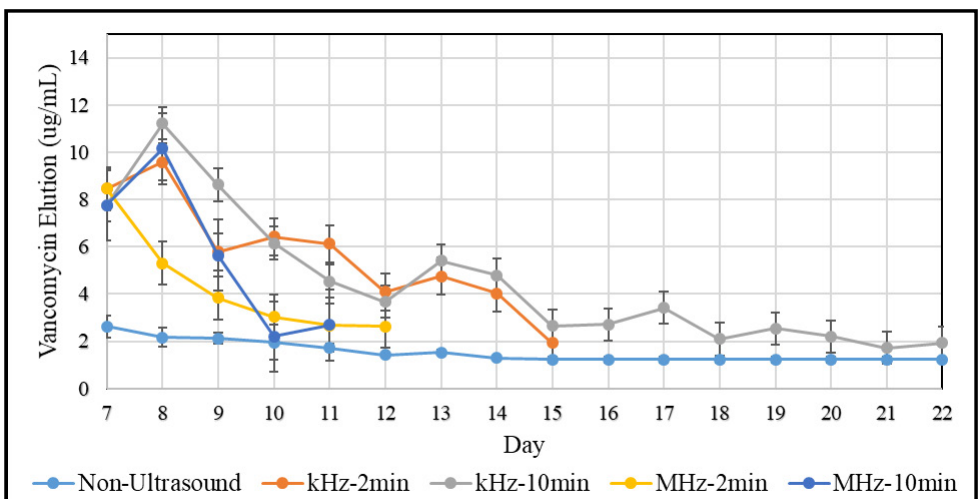

Figure 2. Comparison of daily average elution amounts for non-ultrasound (US) controls and all treatment groups. The top figure shows the entire non-US group elution profile and the US treatment groups for their respective treatment durations. The bottom figure shows both non-US and treatment groups but for only the US treatment period which began on day seven. Error bars in the lower plot indicate \pm one standard deviation.

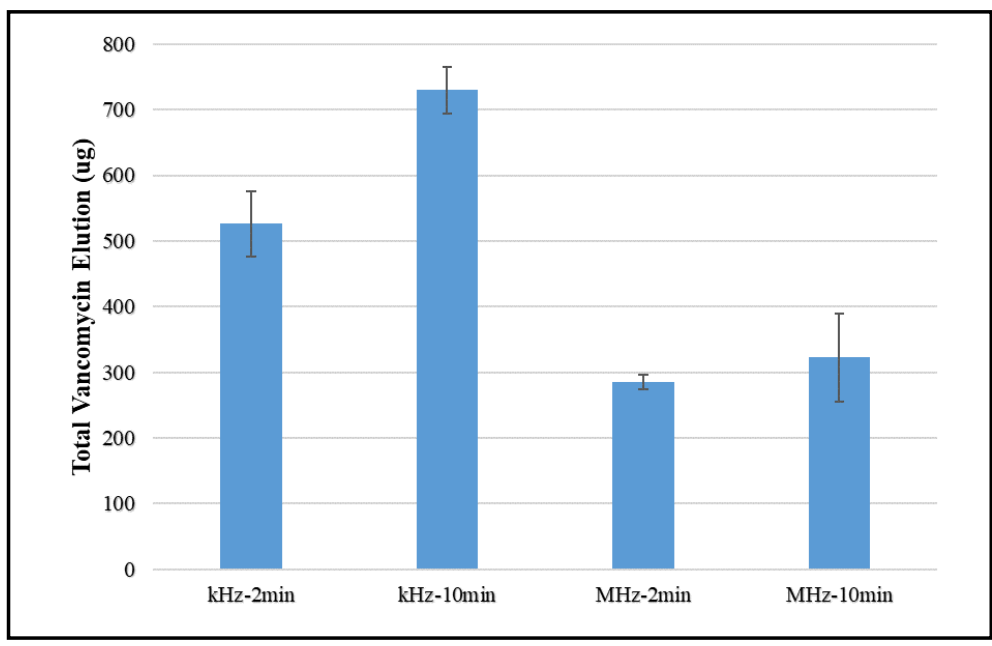

Figure 3. Average net sum of the increased vancomycin elution above nonultrasound (US) elution for combinations of US frequencies and treatment durations. Error bars indicate \pm one standard deviation.

\section{DISCUSSION}

Our baseline vancomycin elution rates were in agreement with previously reported values from studies that utilized similar methodology $y^{20,26}$ and exhibited elution curves which closely match relative profiles observed in-vivo. ${ }^{35,36}$ Both US frequency and treatment duration time had significant effects on increasing antibiotic elution. The $\mathrm{kHz}$ frequency at the longer duration produced both the greatest significant increase in total amount and the
KANSAS JOURNAL of MEDICINE

ULTRASOUND FREQUENCY ONANTIBIOTIC

\section{ELUTION}

continued.
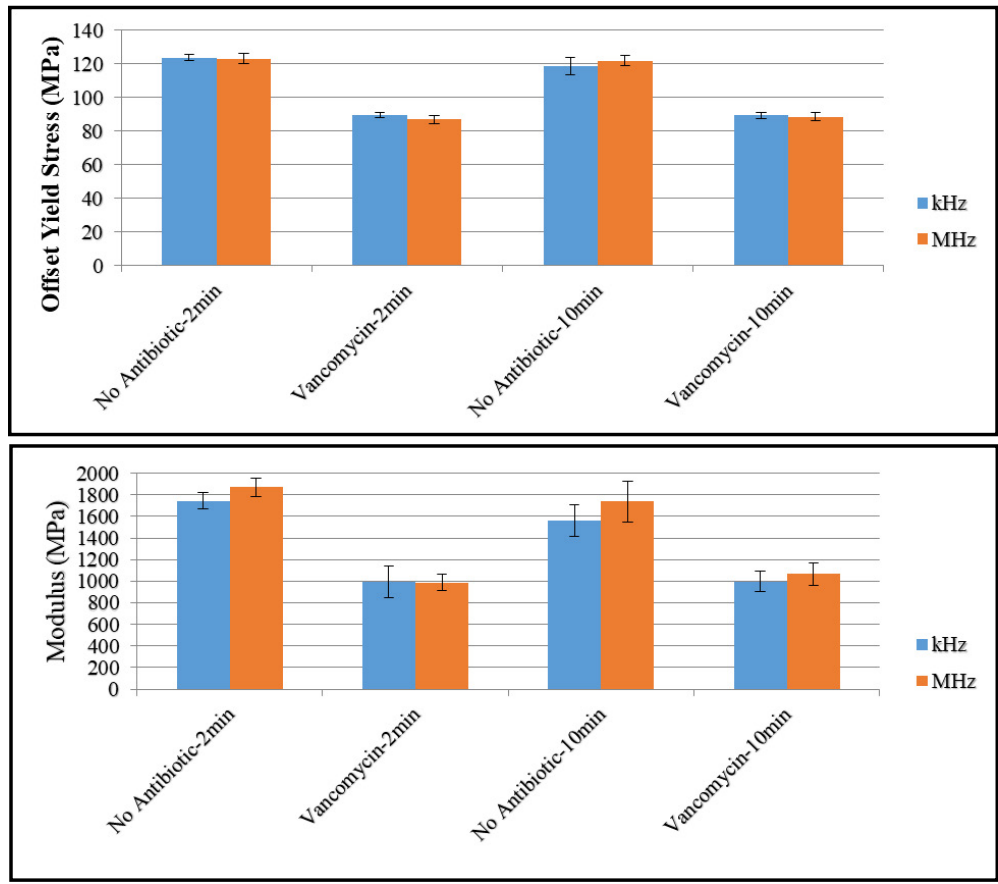

Figure 4. Average values are shown for offset yield stress (top) and elastic modulus (bottom) for no-antibiotic and vancomycin-loaded cement samples at the end of each test group's elution period. Error bars indicate \pm one standard deviation.

longest-sustained increase in antibiotic elution. The MHz frequency at both durations produced significant increases in elution, however, at lesser amounts than the $\mathrm{kHz}$ groups and for fewer days. This was to be expected as higher frequencies are known to see greater attenuation, particularly in more dense materials like bone cement and bone. ${ }^{37}$

The number of days that US significantly increased antibiotic elution ranged from five to 16 . This is similar to the typical length of the primary elution phase which is usually around one week. Given that a six week (42 day) treatment period commonly is used for twostage revision arthroplasty, ${ }^{7}$ the addition of US treatment improves current treatment from around a quarter to roughly half of the typical treatment period. While our study design was such that we were unable to run statistical comparisons based on number of days of significant increases, the results indicated that US treatment may provide a meaningful improvement in the amount of time that the spacer can be used to deliver adequate antibiotic concentrations.

Given that both bone and PMMA cement have relatively high acoustic impedances and quickly dampen the propagation of US waves ${ }^{37}$ the greatest opportunities for increasing antibiotic elution from spacers with US likely exist at the perimeter of the joint space. The most immediately exposed surfaces would include molded spacer surface edges and any exposed backing cement used to anchor the spacers in place. The surface area of the ASTM F451-99a specimens represents only a small fraction of the total surface area of a spacer, likely multiple orders of magnitude smaller. With this in mind, it seems likely that truly meaningful amounts of increased antibiotic 
KANSAS JOURNAL of MEDICINE

ULTRASOUND FREQUENCY ON ANTIBIOTIC ELUTION continued.

elution could be achieved with US treatment. Further investigations are needed to determine what the true US wave propagation and attenuation would be in-vivo and what amount of surface area can effectively be treated to produce increased antibiotic elution.

A key factor in the use of US for long-term antibiotic elution modulation is the relation of elution levels to clinically-based targets such as MIC or MBEC for specific PJIs. In the present study design, the resulting concentrations are highly dependent on independent study parameters including specimen size, PBS storage volume, and amount of antibiotic used. Ultimately, additional biological factors such as patient body habitus, medical comorbidities, and types of organisms involved would need to be considered along with joint space volumes and anticipated elution rates to determine the effectiveness of a particular US treatment strategy.

There is a wide variety of antibiotic treatment durations that are considered adequate or necessary for treatment of PJIs. ${ }^{7,38}$ Given the high amounts of antibiotic that remain entrapped within the cement, ${ }^{14,15}$ there is also a question of whether an antibiotic's effectiveness degrades over time or if its stability is preserved so that its release might be useful. Future investigations are needed to determine if entrapped antibiotics can be utilized for long term PJI treatment.

The mechanical compression test results showed no significant effect of either frequency or treatment duration on offset yield stress and that, as a previous study has shown, the addition of the antibiotic has a greater impact on mechanical properties than treatment with US. ${ }^{26}$ Although there was a significant univariate effect of frequency on elastic modulus, the effect seems small and of less concern clinically compared to the decrease in modulus caused by the addition of the antibiotic itself. The increased total antibiotic elution of the $\mathrm{kHz}$ group compared to the $\mathrm{MHz}$ group may explain the decrease in elastic modulus. It may be possible that greater total elution of antibiotic results in greater mass loss for the bulk material, which in turn results in decreased stiffness. This may, however, be difficult to prove in the presence of ongoing polymerization. ${ }^{39}$

An important aspect to consider is the effect of US treatment on the tissues exposed to US and the physiological responses. Both US devices used in the study were designed primarily for therapeutic effects on subdermal tissues. The overall treatment effectiveness targeting antibiotic loaded cement would need to be balanced with an understanding of the secondary effects on the surrounding tissues. In the case of joint arthroplasty, the secondary effects may provide beneficial improvements in osteogenesis, local blood flow, pharmacokinetics, and adjacent tissue healing, however, additional studies would be necessary to prove the efficacy of such responses. ${ }^{40-42}$

Both frequency and power are relevant US parameters that contribute to the effectiveness of US as a technique for elution modulation. In this study, the use of two different clinical machines meant that, although we attempted to keep the applied intensity consistent, all factors were not controlled for that may have been different between them. Nevertheless, the strategy for the present study was to normalize the effect of US power differences by setting each machine to a similar output intensity and by placing the specimens at equal relative position and distance from each machine's transducer. Such techniques have been utilized in similar studies evaluating effects of US on elution. ${ }^{21,22}$ While more sophisticated laboratory US equipment could be used to compare more precisely specific frequencies, most clinical US machines provide only limited control over power adjustments and it was important to utilize machines more likely to be used in a clinical setting.

When considering US treatment as part of a larger strategy for increasing long-term antibiotic elution, combination with other elution augmentation techniques like modified mixing techniques and the use of additives may have symbiotic effects. ${ }^{26,43}$ The use of US exposure along with incorporation of resorbable filler materials such as poragens or other antibiotics may simultaneously increase filler resorption and antibiotic release. ${ }^{24,43}$ Further study is needed to determine whether combined modulation techniques provide additional benefits beyond simply the sum of individual techniques.

In addition to the previously discussed limitations of a basic invitro environment with limited physiological relation to the true in-vivo environment, only a single antibiotic was tested, and only at a single dosage amount. In the clinical setting, a wide variety of antibiotics are used with dosages chosen based on a variety of patient-specific factors. Future investigations would be required to determine the effects of US frequency and treatment durations for these particular instances. An additional limitation is that only a single specimen size was used. Although ASTM F451-99a is one of the most commonly utilized standards for antibiotic elution studies, its original intent was specifically for mechanical evaluation of cement, and as such, is not optimized for evaluation of elution. Future work should expand beyond this methodology to include environmental and physiological factors that better represent the in-vivo condition and provide improved clinical relevance.

\section{CONCLUSION}

Lower (kHz range) frequency US was able to sustain an increased antibiotic elution rate compared to higher ( $\mathrm{MHz}$ range) frequencies at similar treatment durations. Sustained increases in antibiotic elution were achieved ranging from less than a week to more than two weeks. The effect of US treatment on mechanical properties were minimal and the addition of the antibiotic played the biggest role in reducing offset yield strength and stiffness. The results of this study indicated that varying US frequency and treatment durations allows for elution modulation such that strategies could be devised to achieve either longer-sustained releases at lower amounts or higher releases over shorter periods. Such strategies could allow for improved control and management of PJIs.

\section{ACKNOWLEDGEMENT}

This project was funded by the Marc A. and Elinor C. Asher Orthopedic Research Fund. 


\section{REFERENCES}

Cui Q, Mihalko WM, Shields JS, Ries M, Saleh KJ. Antibiotic-impregnated cement spacers for the treatment of infection associated with total hip or knee arthroplasty. J Bone Joint Surg Am 2007; 89(4):871-882. PMID: 17403814.

${ }^{2}$ Phillips JE, Crane TP, Noy M, Elliott TS, Grimer RJ. The incidence of deep prosthetic infections in a specialist orthopaedic hospital: A 15-year prospective survey. J Bone Joint Surg Br 2006; 88(7):943-948. PMID: 16799001.

Durbhakula SM, Czajka J, Fuchs MD, Uhl RL. Spacer endoprosthesis for the treatment of infected total hip arthroplasty. J Arthroplasty 2004; 19(6):760-767. PMID: 15343538.

${ }^{4}$ Shanmugasundaram S, Ricciardi BF, Briggs TW, Sussmann PS, Bostrom MP. Evaluation and management of periprosthetic joint infection-an international, multicenter study. HSS J 2014; 10(1):36-44. PMID: 24482620.

Wolf M, Clar H, Friesenbichler J, et al. Prosthetic joint infection following total hip replacement: Results of one-stage versus two-stage exchange. Int Orthop 2014; 38(7):1363-1368. PMID: 24638215.

${ }^{6}$ Mortazavi SM, Vegari D, Ho A, Zmistowski B, Parvizi J. Two-stage exchange arthroplasty for infected total knee arthroplasty: Predictors of failure. Clin Orthop Relat Res 2011; 469(11):3049-3054. PMID: 21866421.

Kuzyk PR, Dhotar HS, Sternheim A, Gross AE, Safir O, Backstein D. Twostage revision arthroplasty for management of chronic periprosthetic hip and knee infection: Techniques, controversies, and outcomes. J Am Acad Orthop Surg 2014; 22(3):153-164. PMID: 24603825.

${ }^{8}$ Castaneda P, McLaren A, Tavaziva G, Overstreet D. Biofilm antimicrobial susceptibility increases with antimicrobial exposure time. Clin Orthop Relat Res 2016; 474(7):1659-1664. PMID: 26797908.

Tzeng A, Tzeng TH, Vasdev S, et al. Treating periprosthetic joint infections as biofilms: Key diagnosis and management strategies. Diagn Microbiol Infect Dis 2015; 81(3):192-200. PMID: 25586931.

${ }^{10}$ Zimmerli W, Trampuz A, Ochsner PE. Prosthetic-joint infections. N Engl J Med 2004; 351(16):1645-1654. PMID: 15483283.

$"$ Penner MJ, Duncan CP, Masri BA. The in vitro elution characteristics of antibiotic-loaded CMW and Palacos-R bone cements. J Arthroplasty 1999; 14(2):209-214. PMID: 10065729.

12 Stewart PS, Costerton JW. Antibiotic resistance of bacteria in biofilms. Lancet 2001; 358(9276):135-138. PMID: 11463434.

${ }^{13}$ Ceri H, Olson ME, Stremick C, Read RR, Morck D, Buret A. The Calgary Biofilm Device: New technology for rapid determination of antibiotic susceptibilities of bacterial biofilms. J Clin Microbiol 1999; 37(6):1771-1776. PMID: 10325322

${ }^{14}$ Kuechle DK, Landon GC, Musher DM, Noble PC. Elution of vancomycin, daptomycin, and amikacin from acrylic bone cement. Clin Orthop Relat Res 1991; (264):302-308. PMID: 1705191.

${ }_{15}$ Torholm C, Lidgren L, Lindberg L, Kahlmeter G. Total hipjoint arthroplasty with gentamicin-impregnated cement. A clinical study of gentamicin excretion kinetics. Clin Orthop Relat Res 1983; (181):99-106. PMID: 6641072.

${ }^{16}$ Martinez-Moreno J, Mura C, Merino V, Nacher A, Climente M, MerinoSanjuan M. Study of the influence of bone cement type and mixing method on the bioactivity and the elution kinetics of ciprofloxacin. J Arthroplasty 2015; 30(7):1243-1249. PMID: 25743107.

17 Wahlig H, Dingeldein E. Antibiotics and bone cements. Experimental and clinical long-term observations. Acta Orthop Scand 2009; 51(1):49-56. PMID: 7376844.

18 Masri BA, Duncan CP, Beauchamp CP, Paris NJ, Arntorp J. Effect of varying surface patterns on antibiotic elution from antibiotic-loaded bone cement. J Arthroplasty 1995; 10(4):453-459. PMID: 8523003.

${ }^{19} \mathrm{Li} \mathrm{W}$, Ding Y, Rai R, Roether JA, Schubert DW, Boccaccini AR. Preparation and characterization of PHBV microsphere/45S5 bioactive glass composite scaffolds with vancomycin releasing function. Mater Sci Eng C Mater Biol Appl 2014; 41:320-328. PMID: 24907766.

${ }^{20}$ Amin TJ, Lamping JW, Hendricks KJ, McIff TE. Increasing the elution of vancomycin from high-dose antibiotic-loaded bone cement: A novel preparation technique. J Bone Joint Surg Am 2012; 94(21):1946-1951. PMID 23014891.

${ }^{21}$ Cai XZ, Yan SG, Wu HB, et al. Effect of delayed pulsed-wave ultrasound on local pharmacokinetics and pharmacodynamics of vancomycin-loaded acrylic bone cement in vivo. Antimicrob Agents Chemother 2007; 51(9):3199-3204. PMID: 17620385.

${ }^{22}$ Kummer A, Tafin UF, Borens O. Effect of sonication on the elution of antibiotics from polymethyl methacrylate (PMMA). J Bone Jt Infect 2017; 2(4):208-212. PMID: 29188172.

${ }^{23}$ Broc HS, Moodie PG, Hendricks KJ, McIff TE. Compression strength and porosity of single-antibiotic cement vacuum-mixed with vancomycin. J Arthroplasty 2010;25(6):990-997. PMID: 1967944.
KANSAS JOURNAL of MEDICINE

\section{ULTRASOUND FREQUENCY ON ANTIBIOTIC}

ELUTION

continued.

${ }^{24}$ Nugent M, McLaren A, Vernon B, McLemore R. Strength of antimicrobial bone cement decreases with increased poragen fraction. Clin Orthop Relat Res 2010; 468(8):2101-2106. PMID: 20162384.

${ }_{25}$ Pelletier MH, Malisano L, Smitham PJ, Okamoto K, Walsh WR. The compressive properties of bone cements containing large doses of antibiotics. J Arthroplasty 2009; 24(3):454-460. PMID: 18534462.

26 Wendling A, Mar D, Wischmeier N, Anderson D, McIff T. Combination of modified mixing technique and low frequency ultrasound to control the elution profile of vancomycin-loaded acrylic bone cement. Bone Joint Res 2016; 5(2):26-32. PMID: 26843512.

${ }^{27}$ Lin T,Cai XZ, Shi MM. In vitro and in vivo evaluation of vancomycin-loaded PMMAcement in combination with ultrasound and microbubbles-mediated ultrasound. Biomed Res Int 2015; 2015:309739. PMID: 25632389.

28 Ensing GT, Hendriks JG, Jongsma JE, van Horn JR, van der Mei HC, Busscher HJ. The influence of ultrasound on the release of gentamicin from antibiotic-loaded acrylic beads and bone cements. J Biomed Mater Res B Appl Biomater 2005; 75(1):1-5. PMID: 16044459.

${ }_{29}$ Masri BA, Duncan CP, Beauchamp CP. Long-term elution of antibiotics from bone-cement: An in vivo study using the prosthesis of antibiotic-loaded acrylic cement system. J Arthroplasty 1998; 13(3):331-338. PMID: 9590645.

30 Slane J, Gietman B, Squire M. Antibiotic elution from acrylic bone cement loaded with high doses of tobramycin and vancomycin. J Orthop Res 2017; 36(4):1078-1085. PMID: 28876459.

${ }^{31}$ Osmon DR, Berbari EF, Berendt AR, et al. Diagnosis and management of prosthetic joint infection: Clinical practice guidelines by the Infectious Diseases Society of America. Clin Infect Dis 2013; 56(1): el-e25. PMID: 23223583.

32 Stengel D, Bauwens K, Sehouli J, Ekkernkamp A, Porzsolt F. Systematic review and meta-analysis of antibiotic therapy for bone and joint infections. Lancet Infect Dis 2001; 1(3):175-188. PMID: 11871494.

33 ASTM International. ASTM F451-08 Standard Specification for Acrylic Bone Cement. West Conshohocken, PA: ASTM International, 2015, pp. 117127.

${ }^{34}$ International Organization for Standardization. ISO 5833:2002. Implants for surgery -- Acrylic resin cements. Geneva: ISO, 2013, p. 22.

${ }_{35}$ Anagnostakos K, Wilmes P, Schmitt E, Kelm J. Elution of gentamicin and vancomycin from polymethylmethacrylate beads and hip spacers in vivo. Acta Orthop 2009; 80(2):193-197. PMID: 19404802.

${ }^{36}$ Marra F, Robbins GM, Masri BA, et al. Amphotericin B-loaded bone cement to treat osteomyelitis caused by Candida albicans. Can J Surg 2001; 44(5):383-386. PMID: 11603753.

37 Hendee WR, Ritenour ER. Medical Imaging Physics. New York, NY: Wiley, 2002. ISBN:9780471382263.

${ }_{38}$ Hsieh PH, Huang KC, Lee PC, Lee MS. Two-stage revision of infected hip arthroplasty using an antibiotic-loaded spacer: Retrospective comparison between short-term and prolonged antibiotic therapy. J Antimicrob Chemother 2009; 64(2):392-397. PMID: 19477889.

${ }^{39}$ Nottrott M, Mølster AO, Gjerdet NR. Time dependent mechanical properties of bone cement. An in vitro study over one year. J Biomed Mater Res B Appl Biomater 2007; 83(2):416-421. PMID: 17415769.

${ }_{40}$ Mishima H, Sugaya H, Yoshioka T, et al. The safety and efficacy of combined autologous concentrated bone marrow grafting and low-intensity pulsed ultrasound in the treatment of osteonecrosis of the femoral head. Eur J Orthop Surg Traumatol 2016; 26(3):293-298. PMID: 26920362.

${ }^{41}$ Angle SR, Sena K, Sumner DR, Virdi AS. Osteogenic differentiation of rat bone marrow stromal cells by various intensities of low-intensity pulsed ultrasound. Ultrasonics 2011; 51(3):281-288. PMID: 20965537.

42 Rawool NM, Goldberg BB, Forsberg F, Winder AA, Hume E. Power Doppler assessment of vascular changes during fracture treatment with low-intensity ultrasound. J Ultrasound Med 2003; 22(2):145-153. PMID: 12562119.

${ }^{43}$ Ensing GT, Neut D, van Horn JR, van der Mei HC, Husscher HJ. The combination of ultrasound with antibiotics released from bone cement decreases the viability of planktonic and biofilm bacteria: An in vitro study with clinical strains. J Antimicrob Chemother 2006; 58(6):1287-1290. PMID: 17041238.

Keywords: prosthesis-related infections, arthroplasty, immunosorbent techniques, anti-bacterial agents, ultrasonography 